1. Universidad de Cuenca.

Dirección de Vinculación con la Sociedad. Profesor titular de la carrera de Medicina.

Cuenca - Ecuador

2. Universidad de Cuenca. Facultad de Ciencias Médicas. Docente de la carrera de Medicina.

Cuenca - Ecuador

3. Profesor Principal de la Universidad de Cuenca LlactaLAB - Ciudades Sustentables. Departamento Interdisciplinario de Espacio y Población. Cuenca - Ecuador

4. Universidad de Chile. Facultad de Medicina. Escuela de Salud Pública. Cuenca - Ecuador

\begin{tabular}{c|l}
$\begin{array}{c}\text { Artículo } \\
\text { original }\end{array}$ & $\begin{array}{l}\text { Original } \\
\text { Article }\end{array}$
\end{tabular}

DOI: https://doi.org/10.18537/RFCM.39.01.01

Correspondencia:

david.acurioهucuenca.edu.ec

Dirección:

Salto de la soga s/n y Pájara Pinta

Código Postal:

010114

Celular:

0999240345

Cuenca - Ecuador

\section{Seroprevalencia de la infección de SARS- CoV-2, un estudio transversal. Cuenca - Ecuador, octubre 2020}

\author{
Seroprevalence of SARS-CoV-2 infection, a cross sectional \\ study. Cuenca - Ecuador, October 2020
}

\section{Acurio Páez Fausto David', Vega Crespo Bernardo José2, Orellana Vintimilla Daniel Augusto ${ }^{3}$, Charry Ramírez José Ricardo², Gómez Ayora Andrea Ximena ${ }^{4}$}

\section{RESUMEN}

Objetivo: establecer la seroprevalencia de la infección de SARS-CoV-2 en el cantón Cuenca y su distribución demográfica y socioeconómica.

Metodología: estudio transversal en el cantón Cuenca, basado en muestreo bietápico aleatorizado estratificado con representación de todas las parroquias urbanas y rurales del cantón, con un total de 2457 participantes. Se realizó una encuesta por cada hogar con información socio demográfica y de comportamientos, se detectó anticuerpos para SARS-CoV-2, IgM e IgG en sangre mediante digitopunción.

Resultados: se estimó una seroprevalencia de $10 \%$ (8.4\% a $11.6 \%)$, sin diferencia estadísticamente significativa por sexo y entre el conjunto del área urbano vs. el conjunto del área rural. Las parroquias rurales Tarqui (38.8\%), Checa (36.4\%), tienen seroprevalencias casi tres veces más altas que el promedio cantonal. A menor nivel de instrucción la seroprevalencia es más alta, con un valor $p<0.001$. Los hogares con ingresos menores a $\$ 200$ presentan mayor prevalencia $12.99 \%$ (IC95\%: 8.12-8.19), que los hogares con ingresos superiores a $\$ 1500$ dólares con un $4.74 \%$ (IC95\%: 0.26-12.4).

Conclusiones: en el cantón Cuenca, uno de cada 10 personas presenta anticuerpos contra SARS-CoV-2, la distribución de la enfermedad evidencia diferencias de comportamiento por nivel educativo, parroquia, ingresos económicos y ocupación laboral.

Palabras clave: estudios seroepidemiológicos, virus del SARS, infecciones por coronavirus, SARS-CoV-2, clase social. 


\section{ABSTRACT}

Objective: to establish the seroprevalence of SARS-CoV-2 infection in Cuenca canton and its demographic and socioeconomic distribution.

Methodology: It is a cross-sectional study developed in Cuenca, It is based on a stratified randomized two-stage sampling with representation of all urban and rural parishes of the canton, with a total of 2457 participants. A survey was carried out for each household with sociodemographic and behavioral information, antibodies for SARSCoV-2, IgM and IgG in blood were detected by acupressure.

Results: a seroprevalence of $10 \%$ was estimated, ( $8.4 \%$ to $11.6 \%)$, with no statistically significant difference by sex and between the urban area as a whole vs. the whole of the rural area. The rural parishes Tarqui $(38.8 \%)$, Checa $(36.4 \%)$, have seroprevalences almost three times higher than the cantonal average. At a lower level of education, seroprevalence is higher, with a $p$ value $<0.001$. Households with incomes below $\$ 200$ have a higher prevalence of $12.99 \%$ (95\% Cl: 8.12-18.19), than households with incomes above $\$ 1500$ with $4.74 \%$ (95\% Cl: 0.26-12.4).

Conclusions: in Cuenca, one out of every 10 people has antibodies against SARS-CoV-2, the distribution of the disease shows differences in behavior by educational level, parish, income and work occupation.

Key words: seroepidemiologic studies, SARS virus, coronavirus infections, SARS-CoV-2, social class.

\section{INTRODUCCIÓN}

El 31 de diciembre de 2019, la Organización Mundial de la Salud (OMS) recibió una notificación de un brote de neumonía viral desconocido, la enfermedad, ahora llamada coronavirus 2019 (COVID-19), es causada por el coronavirus 2 del síndrome respiratorio agudo severo (SARS-CoV-2) y se ha extendido a 188 países, causando 104524212 infecciones y al menos 2265850 muertes hasta el 3 de febrero de 2021 , de ellas el $49 \%$ en la región de las Américas ${ }^{1}$; además, ha mostrado que se distribuye de manera diferenciada según factores socioeconómicos y demográficos ${ }^{2,3}$.

El 29 de febrero de 2020 Ecuador conoció el primer caso confirmado de COVID-19, que se expandió de manera rápida por todo el país, primero a las ciudades con mayor población y actividad económica, Guayaquil y Quito 4 .

La velocidad de propagación de la enfermedad llevó a que el 16 de marzo se decrete un estado de excepción que incluyó el cierre de servicios públicos, el 19 de septiembre el Gobierno Nacional levantó el estado de excepción, flexibilizando la movilidad y las restricciones de concentración de personas. Al 3 de febrero de 2021 el país reporta 251279 casos confirmados y 14915 fallecidos por COVID-194.

En el cantón Cuenca el primer caso confirmado de COVID-19 se dio el 14 de marzo de 2020 y el 3 de febrero de 2021 el reporte oficial registra 12794 casos confirmados ${ }^{4}$.

La información oficial está sustentada en los registros rutinarios de los servicios de salud y genera un subregistro entendible; por ello diversos países han desarrollado estudios de seroprevalencia de infección de SARS-CoV-2 mediante la medición de inmunoglobulinas $\operatorname{lgG}$ e $\operatorname{lgM}^{5}$. Cuando los anticuerpos IgM están presentes, pueden indicar una infección activa o reciente, en cambio los anticuerpos IgG una infección pasada ${ }^{6}$.

Por lo dicho, el presente estudio buscó conocer la seroprevalencia de COVID-19, SARS-CoV-2 en el cantón Cuenca y su distribución según condiciones socioeconómicas con la intención de que los resultados permitan tomar decisiones y construir políticas públicas para enfrentar la enfermedad a nivel local. 


\section{METODOLOGÍA}

Estudio seroepidemiológico observacional analítico, transversal, de la infección de SARSCoV-2, en el cantón Cuenca, con dos componentes: a) estimación de la seroprevalencia de la infección utilizando pruebas inmunológicas rápidas que valoran $\operatorname{lgG}$ e IgM más una confirmación con PCR en los casos de reactividad en la prueba rápida; b) aplicación de una encuesta de hogar con preguntas sobre las condiciones socioeconómicas, conocimientos sobre COVID-19 y prácticas de prevención.

El universo de estudio son las 636996 personas que habitan en el cantón Cuenca según la proyección oficial del Instituto Nacional de Estadísticas y Censos (INEC), de los cuales el 65.64\% (418 152) viven en el área urbana $34.35 \%$ (218 844) en el área rural ${ }^{7}$.

El tamaño muestral se calculó en base a un muestreo bietápico aleatorizado estratificado en el que el primer nivel de estratificación estuvo constituido por la totalidad de las parroquias urbanas y rurales de Cuenca, obteniendo un tamaño muestral de 1219 personas para el área urbana y 1217 para el área rural. Para el cálculo del tamaño muestral se ha utilizado la fórmula útil para poblaciones finitas que se expresa de la siguiente manera:

$$
n=\frac{N *\left(Z_{1-\alpha}\right)^{2} *(p * q)}{d^{2} *(N-1)+\left(Z_{1-\alpha}\right)^{2} *(p * q)}
$$

Para el área urbana de Cuenca se utiliza los siguientes valores:

- N: Población total de 418152

- Un Valor de Z, correspondiente al nivel de significación (95\%) deseado. Z1-a = 1.96

- Proporción estimada en el momento de la encuesta. $p=(50 \%)=0.50$

- Grado de precisión deseado $(97 \%) d=3 \%$

$$
n=\frac{418152 *(1.96)^{2} *(0.50 * 0.50)}{0.03^{2} *(418151)+(1.96)^{2} *(0.50 * 0.50)}
$$

$$
n=1108
$$

Para el área rural de Cuenca se planean la misma fórmula con las siguientes referencias:
- $\mathrm{N}: 218844$ habitantes

- Proporción estimada en el momento de la encuesta. $p=(50 \%)=0.50$

- Un Valor de Z, correspondiente al nivel de significación (95\%) deseado. $Z_{1-\mathrm{a}}=1.96$

- Grado de precisión deseado $(97 \%)$ d = 3\%

$$
n=\frac{218844 *(1.96)^{2} *(0.50 * 0.50)}{0.03^{2} *(218843)+(1.96)^{2} *(0.50 * 0.50)}
$$

$$
n=1106
$$

- $\mathrm{n}=1106+10 \%$ por posibles pérdidas (Normas Consort)

$$
\mathrm{n}=1106+111 \quad \rightarrow \quad \mathrm{n}=\mathbf{1 2 1 7}
$$

Un tamaño muestral es de $\mathbf{2} \mathbf{4 3 6}$ participantes en todo el cantón.

Una vez definido el tamaño muestral global para el área urbana y la rural se distribuyó la muestra proporcionalmente a la población de cada una de las 15 parroquias urbanas y 21 parroquias rurales del cantón.

\section{Tabla $N^{\circ} 1$}

Distribución de la muestra por parroquias urbanas de Cuenca

\begin{tabular}{lccc}
\hline $\begin{array}{l}\text { Parroquias } \\
\text { Urbanas }\end{array}$ & $\begin{array}{c}\text { Población } \\
\mathbf{2 0 2 0}\end{array}$ & $\begin{array}{c}\text { Proporción } \\
\text { para el } \\
\text { estudio (\%) }\end{array}$ & $\begin{array}{c}\text { Muestra } \\
\text { para } \\
\text { estudio }\end{array}$ \\
\hline Gil Ramírez & 8947 & 2.1 & 26 \\
Dávalos & 38353 & 9.2 & 112 \\
Totoracocha & 14951 & 3.6 & 44 \\
Cañaribamba & 8533 & 2.0 & 25 \\
El Sagrario & 37728 & 9.0 & 110 \\
El Vecino & 12296 & 2.9 & 36 \\
San Blas & 21586 & 5.2 & 63 \\
Sucre & 41214 & 9.9 & 120 \\
Bellavista & 29876 & 7.1 & 87 \\
El Batan & 65104 & 15.6 & 190 \\
Yanuncay & 46728 & 11.2 & 136 \\
San Sebastián & 20489 & 4.9 & 60 \\
Huayna Capac & 20.9 & 62 \\
Monay & 21220 & 5.1 & 64 \\
Hermano Miguel & 21905 & 5.2 & 85 \\
Machángara & 29221 & 7.0 & 1219 \\
\hline Total & 418152 & 100 &
\end{tabular}




\section{Tabla $\mathrm{N}^{\circ} 2$}

Distribución de la muestra por parroquias rurales de Cuenca

\begin{tabular}{|c|c|c|c|}
\hline $\begin{array}{l}\text { Parroquias } \\
\text { Rurales }\end{array}$ & $\begin{array}{c}\text { Población } \\
2020\end{array}$ & $\begin{array}{c}\text { Proporción } \\
\text { para el } \\
\text { estudio (\%) }\end{array}$ & $\begin{array}{c}\text { Muestra } \\
\text { para } \\
\text { estudio }\end{array}$ \\
\hline Baños & 21231 & 9.7 & 118 \\
\hline Chaucha & 1634 & 0.7 & 9 \\
\hline Checa & 3453 & 1.6 & 19 \\
\hline Chiquintad & 6080 & 2.8 & 34 \\
\hline Cumbe & 6988 & 3.2 & 39 \\
\hline Llacao & 6730 & 3.1 & 37 \\
\hline Molleturo & 9029 & 4.1 & 50 \\
\hline Nulti & 5448 & 2.5 & 30 \\
\hline $\begin{array}{l}\text { Octavio } \\
\text { Cordero }\end{array}$ & 2861 & 1.3 & 16 \\
\hline Paccha & 8148 & 3.7 & 45 \\
\hline Quingeo & 9386 & 4.3 & 52 \\
\hline Ricaurte & 24393 & 11.1 & 136 \\
\hline San Joquín & 9393 & 4.3 & 52 \\
\hline Santa Ana & 6761 & 3.1 & 38 \\
\hline Sayausí & 10573 & 4.8 & 59 \\
\hline Sidcay & 4994 & 2.3 & 28 \\
\hline Sinincay & 19981 & 9.1 & 111 \\
\hline Tarqui & 13217 & 6.0 & 74 \\
\hline Turi & 11294 & 5.2 & 63 \\
\hline El Valle & 30634 & 14.0 & 170 \\
\hline $\begin{array}{l}\text { Victoria del } \\
\text { Portete }\end{array}$ & 6616 & 3.0 & 37 \\
\hline Total Rural & 218844 & 100 & 1217 \\
\hline
\end{tabular}

La selección de los hogares participantes de cada parroquia se basó en una aleatorización basada en los predios catastrados por la municipalidad y los medidores de luz; dentro del hogar también se procedió a seleccionar de manera aleatoria a la persona a participar. Para lograr mayor representatividad de menores de 5 años, se incrementó la muestra con 21 niños con lo cual la muestra efectiva fue de 2457 participantes.

Se realizó una encuesta por cada hogar con información socio demográfica y de comportamientos frente a la normativa preventiva vigente, en la misma visita se tomó una muestra de sangre mediante digito punción para la detección de anticuerpos para SARS-CoV-2 con una prueba marca Standard Q COVID-19 lgM/lgG duo con una sensibilidad de $94.33 \%$ hasta antes de los siete días del inicio de síntomas y una especificidad de $95.19 \%{ }^{1}$.

Los datos fueron recolectados en tablets y teléfonos celulares en el software KoBoToolbox, luego migrados a Excel, SPSS 15 y R versión 4.0.3 para el procesamiento y análisis de los datos obtenidos.

La base de datos fue revisada para identificar datos faltantes; se estimaron medidas de frecuencia y tendencia central con sus respectivos intervalos de confianza al $95 \%$. Las prevalencias, total y por variables de interés, todos ellos fueron ajustados para el marco muestral y la sensibilidad y especificidad de la prueba, con su respectivo intervalo de confianza al 95\% mediante análisis Bayesiano

\section{RESULTADOS}

La muestra estudiada fue de 2457 personas, de ellas el $59.4 \%$ (1 460) fueron mujeres y el $40.6 \%$ varones. La edad media de los participantes fue de 39.34 años, con un rango de edad que va desde menores de un año hasta 92 años.

El cálculo de la seroprevalencia estima a todas aquellas personas que al momento de la encuesta y realización de la prueba de anticuerpos para SARS-CoV-2 tuvieron resultados positivos para IgG, IgM o para ambas. En base a esta consideración se estableció una seroprevalencia aparente de $13.2 \%$ en la totalidad del cantón Cuenca. Al ajustar estos valores, en función de la sensibilidad y especificidad de la prueba utilizada, estimamos una seroprevalencia final de 10\% (8.4\% y $11.6 \%)$, para el conjunto del cantón Cuenca.

La seroprevalencia en mujeres fue de $10.82 \%$ (IC95\%: 6.81-14.97), ligeramente mayor que en hombres 7.95\% (IC95\%: 3.74-12.3), sin diferencia estadísticamente significativa.

No se observan diferencias estadísticamente significativas en las prevalencias por grupo de edad, no se encontraron casos en menores de 1 año y la prevalencia más elevada fue en el grupo de 30 a 49 años con un $11.74 \%$ (IC95\%: 7.21\%-16.42) (Imagen $\left.N^{\circ} 1\right)$ 


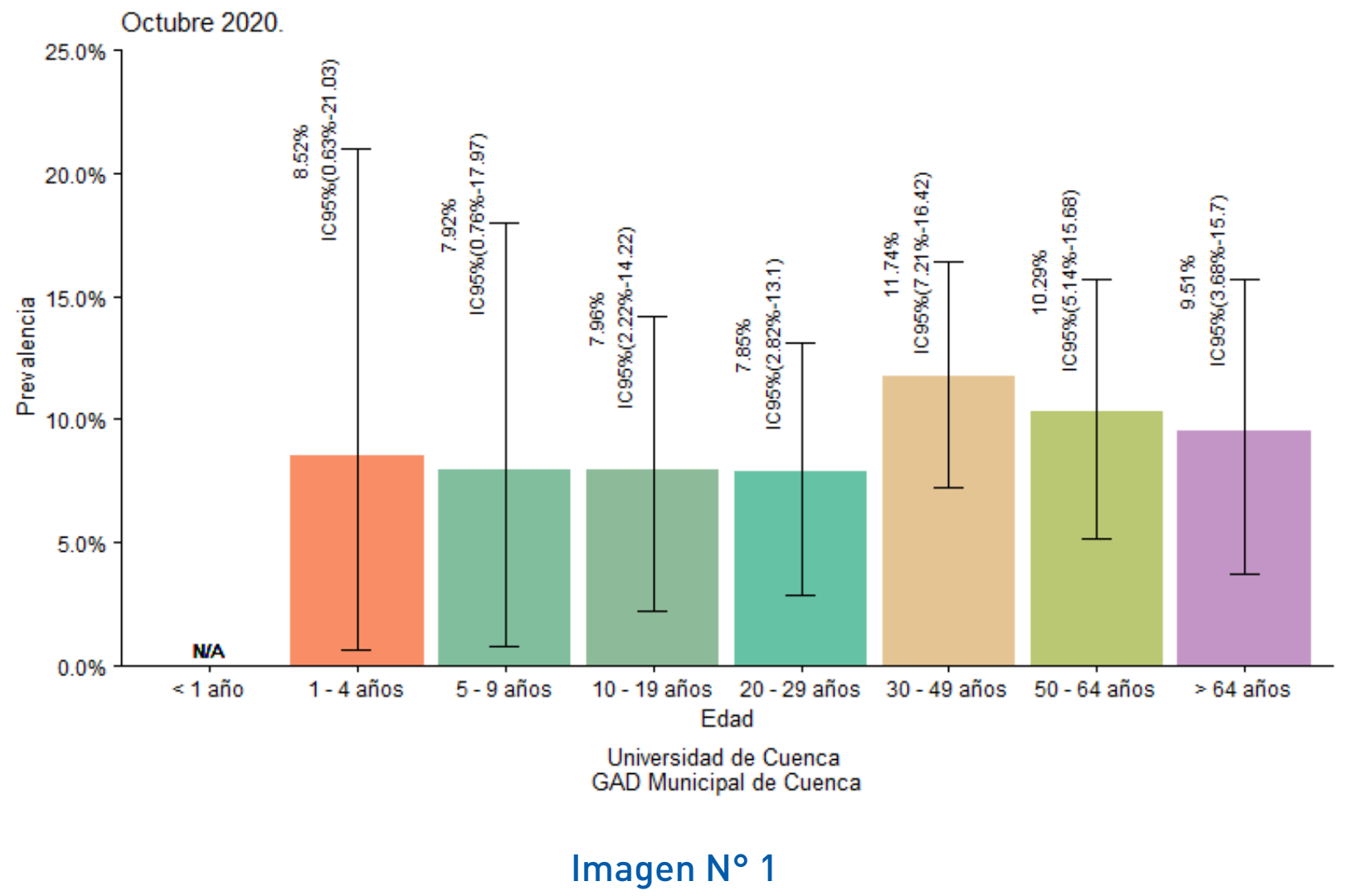

Seroprevalencia estimada de SARS-CoV-2 por grupo etario. Cuenca - Ecuador

La prevalencia es ligeramente superior en el área rural $10.36 \%$ (IC95\%: 8.06\%-1167\%) que en el área urbana $9.4 \%$ (IC95\%: 7.16-11.67) pero no es una diferencia estadísticamente significativa.

La situación en cada una de las parroquias se puede ver en las Imágenes $\mathrm{N}^{\circ} 1$ y $\mathrm{N}^{\circ} 2$. En el área rural, parroquias como Tarqui $(38.8 \%)$, Checa (36.4\%) tienen seroprevalencias casi tres veces más altas que el promedio cantonal, pero Molleturo (19.9\%), Sidcay (18.9\%), Turi $(17.7 \%)$, Santa Ana (16.3\%), Victoria del Portete (15.7\%), Sinincay $(15.1 \%)$, tienen valores superiores al promedio cantonal (Imagen $\mathrm{N}^{\circ} 2$ ). 


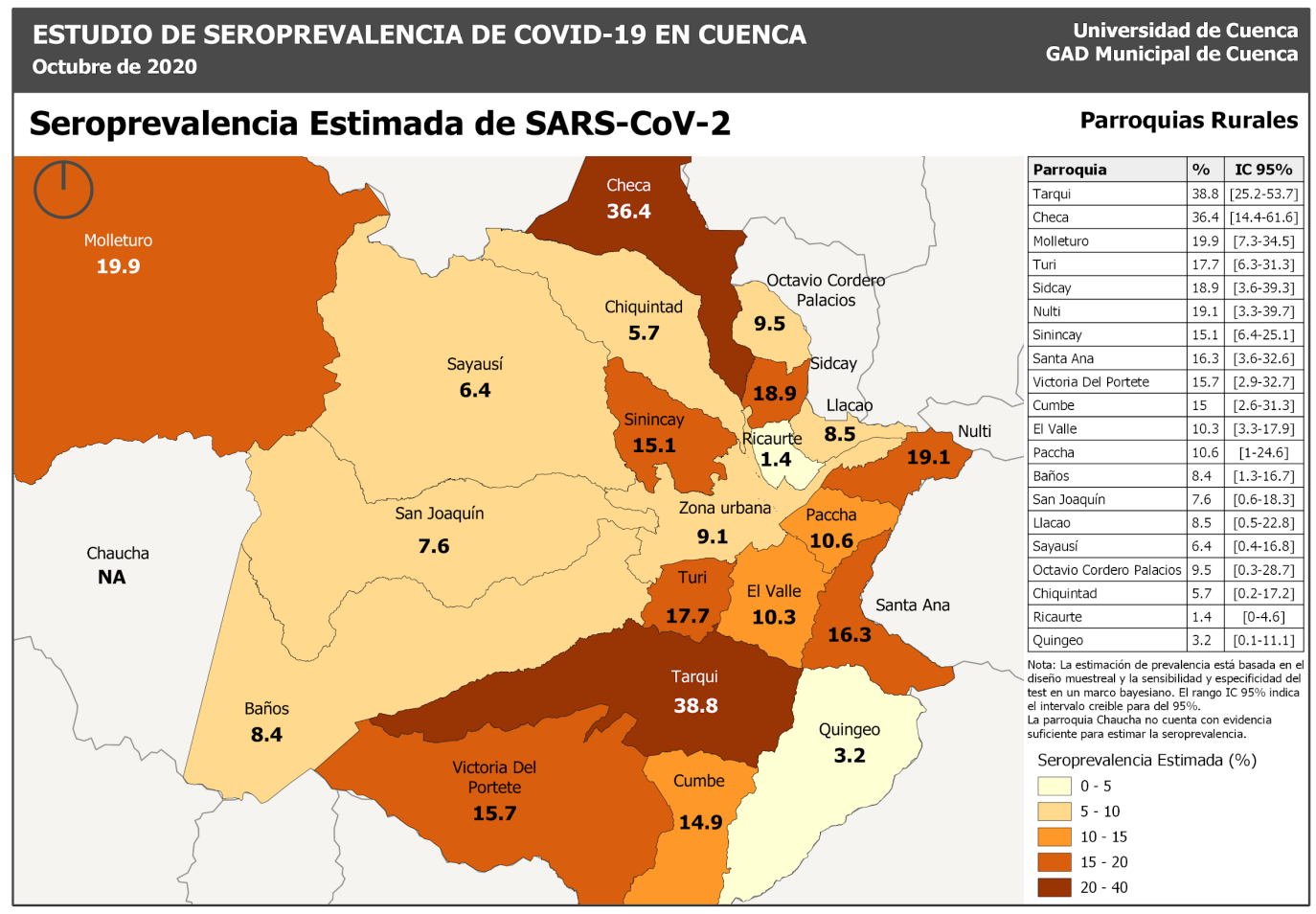

Imagen $\mathrm{N}^{\circ} 2$

Seroprevalencia de COVID-19 en 1231 personas de las parroquias rurales del cantón Cuenca octubre 2020

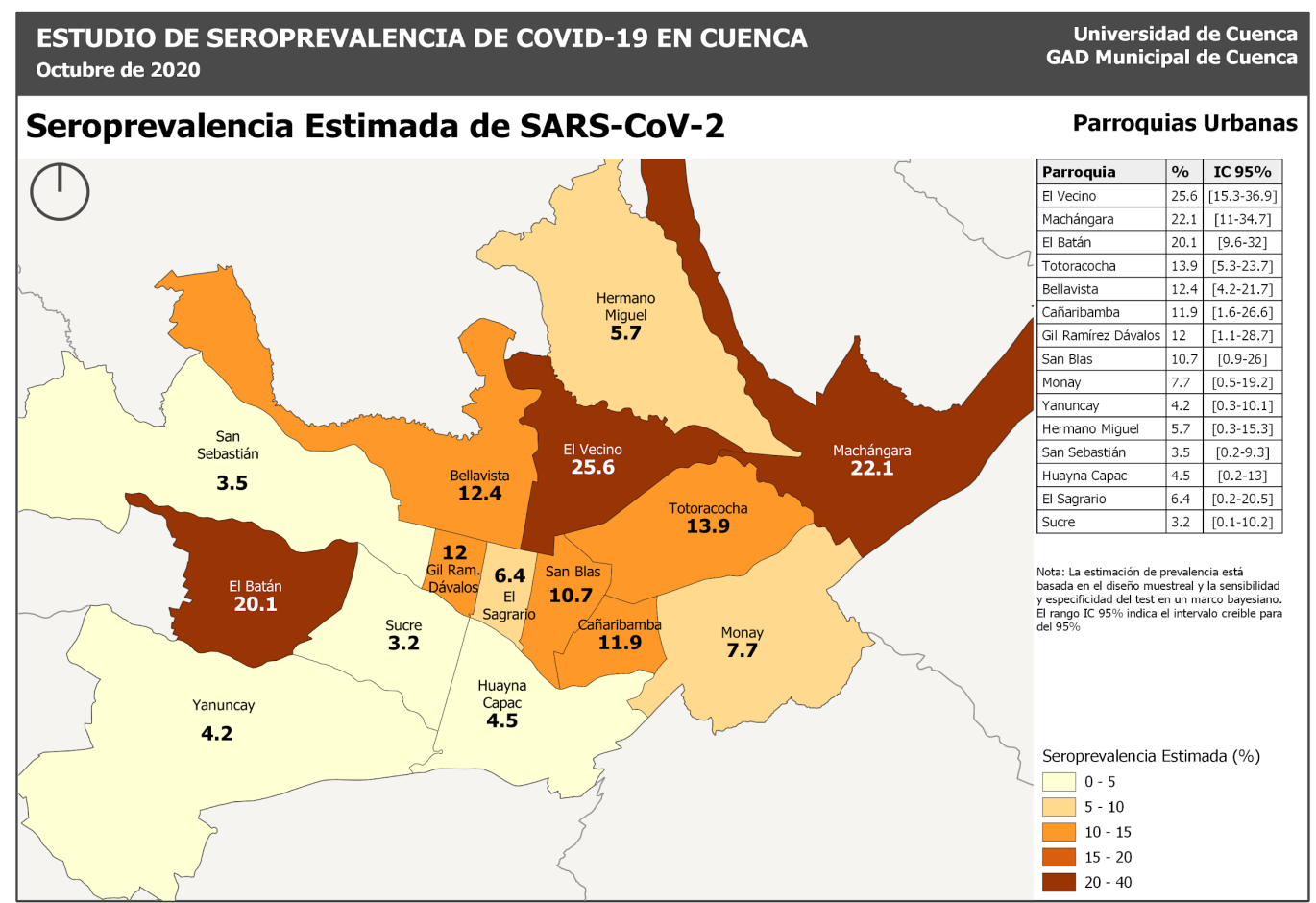

Imagen $\mathrm{N}^{\circ} 3$

Seroprevalencia de COVID-19 en 1217 personas de las parroquias urbanas del cantón Cuenca octubre 2020. 
En el área urbana las parroquias: El Vecino (25.6\%), Machángara (22.1\%), El Batán (20.1\%) mantienen porcentajes dos veces más altos de la seroprevalencia cantonal promedio, luego Totoracocha (13.9\%), Gil Ramírez (12\%) y Cañaribamba (11.9\%) también tienen prevalencias superiores al promedio (Imagen $\mathrm{N}^{\circ} 3$ ).

La seroprevalencia en los hogares con un jefe de hogar que declara no tener ningún nivel de instrucción es del $12.4 \%$, con instrucción primaria del $14.82 \%$, con educación secundaria del $9.55 \%$, instrucción superior del $3.29 \%$, con un valor $p<0.001$ (Tabla $\mathrm{N}^{\circ} 3$ ).

La seroprevalencia es casi dos veces mayor en las personas que han tenido dificultades de adquirir alimentos (15.93\%), frente a quienes no la han tenido $(8.25 \%)$ con un valor $p=0.001$. Los hogares que no cuentan con recursos suficientes, la seroprevalencia promedio de SARS-CoV-2 es de 14.31\%; quienes cuentan con recursos suficientes para enfrentar la pandemia tienen una seroprevalencia de $7.55 \%$ (Tabla $\mathrm{N}^{\circ} 3$ ).

Al relacionar la principal fuente de ingresos del jefe de hogar con la seroprevalencia de SARS-CoV-2, se evidencia que cuando el ingreso principal es la venta ambulante o el jornal, la seroprevalencia es de $30.31 \%$ y $17.8 \%$ respectivamente, muy superiores al promedio cantonal $(10 \%)$, mientras que los que viven de un sueldo fijo (9.21\%) un negocio particular $(7.92 \%)$ o de una pensión jubilar (7.28\%) tienen seroprevalencias por debajo del promedio (Tabla $\mathrm{N}^{\circ} 3$ ).

\section{Tabla $\mathrm{N}^{\circ} 3$}

Seroprevalencia de COVID-19 en el cantón Cuenca y variables sociodemográficas, octubre de 2020

\begin{tabular}{|c|c|c|c|c|}
\hline & Positivo & Negativo & Prevalencia (IC95\%) $^{\mathrm{a}}$ & Valor $p$ \\
\hline Nivel de instrucción & & & & $<0.001$ \\
\hline Ninguno & 15 & 103 & $12.14(3.51-21.98)$ & \\
\hline Primaria o menor & 148 & 853 & $14.82(10.17-19.69)$ & \\
\hline Secundaria & 116 & 882 & $9.55(5.14-14.12)$ & \\
\hline Superior & 45 & 602 & $3.29(0.2-7.2)$ & \\
\hline $\begin{array}{l}\text { ¿Cuál es su principal fuente de } \\
\text { ingresos? }\end{array}$ & & & & 0.004 \\
\hline Pensión jubilar & 15 & 141 & $7.36(1.02-14.92)$ & \\
\hline Negocio particular & 76 & 646 & 7.95(3.31-12.65) & \\
\hline Sueldo & 93 & 722 & $9.34(4.79-14.09)$ & \\
\hline Jornal diario o por semana & 25 & 129 & $17.9(9.17-27.7)$ & \\
\hline Ventas ambulantes & 14 & 48 & $30.34(15.59-47.29)$ & \\
\hline Otro & 29 & 190 & $12.53(5.39-20.19)$ & \\
\hline Ocupación & & & & $<0.001$ \\
\hline Artesano & 25 & 163 & $12.75(5.38-20.86)$ & \\
\hline $\begin{array}{l}\text { Comerciante propietario de pequeño } \\
\text { negocio }\end{array}$ & 43 & 350 & $8.65(3.14-14.44)$ & \\
\hline $\begin{array}{l}\text { Empleada doméstica - ayudante fa- } \\
\text { miliar sin remuneración }\end{array}$ & 12 & 36 & $35.67(17.5-55.55)$ & \\
\hline $\begin{array}{l}\text { Empleado de empresa particular no } \\
\text { titulado }\end{array}$ & 26 & 223 & $8.14(2.06-14.85)$ & \\
\hline $\begin{array}{l}\text { Empleado de empresa particular } \\
\text { titulado (profesional o técnico) }\end{array}$ & 11 & 135 & $4.83(0.33-11.53)$ & \\
\hline
\end{tabular}




\begin{tabular}{|c|c|c|c|c|}
\hline & Positivo & Negativo & Prevalencia (IC95\%) ${ }^{a}$ & Valor $p$ \\
\hline $\begin{array}{l}\text { Empleado público titulado (profesio- } \\
\text { nal o técnico) }\end{array}$ & 22 & 144 & $12.79(4.98-21.43)$ & \\
\hline Jornalero o peón & 12 & 80 & $12.86(3.43-24.29)$ & \\
\hline Jubilado & 10 & 121 & $5.11(0.34-12.21)$ & \\
\hline $\begin{array}{l}\text { Obrero o trabajador manual de em- } \\
\text { presa no propia }\end{array}$ & 15 & 81 & $17.09(6.8-29.09)$ & \\
\hline Pequeño trabajador agrícola & 26 & 85 & $31.78(19.62-45.02)$ & \\
\hline $\begin{array}{l}\text { Profesional o técnico que ejerce in- } \\
\text { dependientemente }\end{array}$ & 17 & 136 & $9.43(2.22-17.81)$ & \\
\hline $\begin{array}{l}\text { Trabajador por cuenta propia ni pro- } \\
\text { fesional ni técnico }\end{array}$ & 10 & 71 & $11.97(2.65-23.3)$ & \\
\hline Otro & 27 & 166 & $13.82(6.17-21.95)$ & \\
\hline Recursos suficientes para subsistir & & & & $<0.001$ \\
\hline $\mathrm{Si}$ & 192 & 1671 & 7.53(3.59-11.39) & \\
\hline No & 133 & 786 & $14.28(9.55-19.23)$ & \\
\hline Dificultades para adquirir alimentos & & & & 0.001 \\
\hline $\mathrm{Si}$ & 80 & 439 & $16.07(10.52-22)$ & \\
\hline No & 239 & 1965 & $8.27(4.52-12.17)$ & \\
\hline $\begin{array}{l}\text { Causas que dificultan conseguir } \\
\text { alimentos }\end{array}$ & & & & $<0.001$ \\
\hline Sensación de inseguridad & 14 & 92 & $12.94(3.81-23.42)$ & \\
\hline Costo de alimentos & 117 & 660 & $15.28(10.34-20.41)$ & \\
\hline No he tenido dificultades & 165 & 1481 & $7.08(3.12-11.07)$ & \\
\hline
\end{tabular}

${ }^{a}$ prevalencias ajustadas por el método Bayesiano, para el ajuste se eliminaron casos perdidos.

Las actividades como el empleo doméstico $(35.6 \%)$ y el pequeño trabajador agrícola $(31.6 \%)$ tienen una seroprevalencia tres veces mayores al promedio cantonal (10\%). Los obreros y trabajadores manuales tienen una seroprevalencia del $17.12 \%$, mientras los empleados titulados de empresa particular de $4.87 \%$ (Tabla $\mathrm{N}^{\circ} 3$ ).

La condición económica de las familias tiene clara correlación con la seroprevalencia de
SARS-CoV-2, los hogares con ingresos menores a US\$200 presentaron la mayor prevalencia 12.99\% (IC95\%: 8.12-18.19), mientras que los hogares con ingresos superiores a US $\$ 1500$ la menor prevalencia con un 4.74\% (IC95\%: 0.2612.4), diferencias que son estadísticamente significativas con un valor $p<0.05$, como se puede ver en la imagen $\mathrm{N}^{\circ} 4$. 


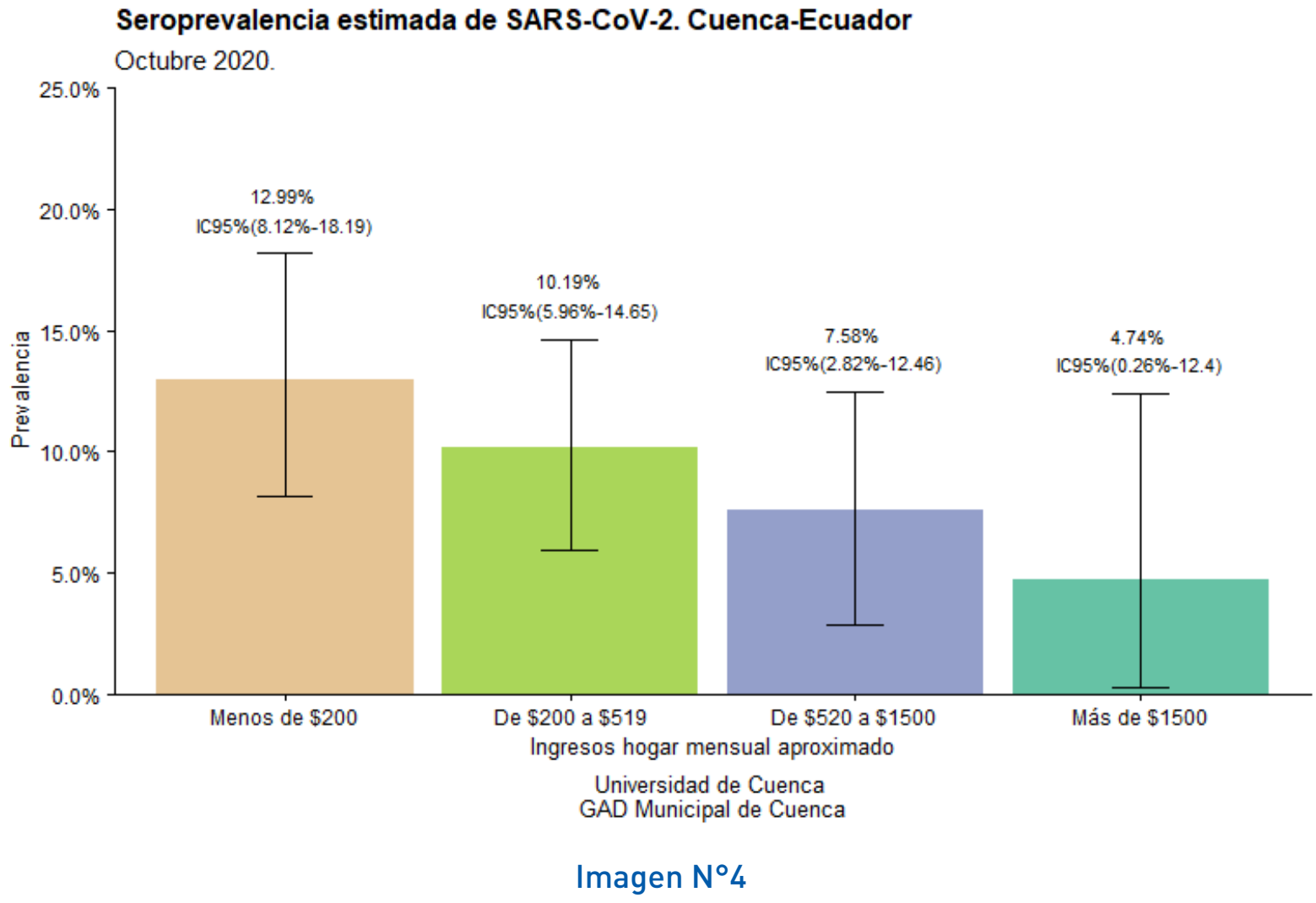

Seroprevalencia estimada de SARS-CoV-2 por ingresos del hogar. Cuenca-Ecuador

\section{DISCUSIÓN}

La presente investigación estimó una seroprevalencia de infección de SARS-CoV-2 de $10 \%$, cercana a la encontrada en Suiza en donde se observó un $10.8 \%$ en mayo de $2020^{8}$, mayor a la encontrada en España con un $5 \%^{3}$.

En una revisión sistemática realizada por Rostami y cols $^{9}$, concluyeron que en la población general la prevalencia poblacional de anticuerpos IgM y/o lgG para SARS-CoV-2 se encuentra entre el $0.37 \%$ al $22.1 \%$, con una estimación combinada del $3.38 \%$ (IC95\%: $3.05-3.72 \%$ ), en el caso de América del Sur del 1.45\% (0.95-1.94\%), observándose una mayor prevalencia en Irán $(22.1 \%)$, Suecia $(15.02 \%)$ y Chile $(10.7 \%)$.

En el estudio no se observaron diferencias significativas según sexo, esto concuerda con lo encontrado en la literatura internacional, en donde hombres y mujeres presentan la misma probabilidad de desarrollar anticuerpos contra SARS-CoV-23,8,9. Tampoco existen diferencias estadísticamente significativas por edad; sin embargo, se observan mayores prevalencias desde los 30 años en adelante concordando con lo que se observa a nivel internacional ${ }^{3}$.

Cuando menor es el nivel de instrucción, más alta es la seroprevalencia de SARS-CoV-2, jefes de hogar con instrucción primaria mostraron mayor frecuencia de contacto con el virus $(14.8 \%)$ que quienes tenían instrucción superior (3.29\%). Estos resultados son similares a los encontrados en Brasil, en donde quienes tenían 12 o más años de escolaridad presentaron una prevalencia más baja que aquellos con menos educación ${ }^{2}$.

En el presente estudio los hogares con ingresos menores a US $\$ 200$, presentan mayor prevalencia que hogares con ingresos superiores a US $\$ 1500$, resultados que coinciden con lo encontrado en Brasil que encuentra que los individuos del quintil más pobre tuvieron 2.16 veces más probabilidades de presentar un resultado positivo (IC 95\%: 1.86 2.51) que los del quintil más rico ${ }^{2}$.

Una limitación del presente estudio, es la mayor representación de mujeres en la encuesta, la misma que puede deberse a que la metodología supuso la visita a domicilios; sin embargo, esta 
mayor representación no mostró una diferencia significativamente estadística, por lo que no existe sobrerrepresentación que afecta los resultados del estudio.

Las pruebas de anticuerpos son útiles para identificar infecciones asintomáticas, determinar la seroprevalencia en una población específica y realizar un seguimiento de la progresión ${ }^{6}$, por lo que es importante el continuo monitoreo en el cantón y en el país.

\section{CONCLUSIONES}

El estudio establece claras relaciones entre la seroprevalencia de SARS-CoV-2 y las condiciones socio-económicas, demográficas del cantón Cuenca.

El nivel de instrucción tiene una relación inversamente proporcional a la seroprevalencia de infección por SARS-CoV-2, similar a lo que sucede con el nivel de ingresos, pues a menor nivel de ingresos más alta es la seroprevalencia de SARS-CoV-2, con diferencias de 3 veces a uno entre aquellos que ganan más y los que ganan menos.

Las condiciones socio económicas y particularmente las relacionadas con el tipo de trabajo, son determinantes en la forma de distribución de la enfermedad, así en el grupo de personas que realizan ventas ambulantes hay una seroprevalencia tres veces mayor al promedio cantonal, mientras que aquellos que viven de un sueldo fijo o un negocio particular tienen seroprevalencias por debajo del promedio.

Las actividades como el empleo doméstico y el pequeño trabajo agrícola tienen seroprevalencias tres veces mayores al promedio cantonal. Los obreros y trabajadores manuales tienen seroprevalencias casi dos veces más altas que el promedio, mientras los empleados titulados de empresas particulares tienen una seroprevalencia equivalente a la mitad del promedio.

Una seroprevalencia del $10 \%$ para el conjunto del cantón Cuenca está relacionado con factores que podrían jugar un rol protector ya que tiene la mayor tasa de empleo adecuado/pleno a nivel nacional (64\%), con un promedio de 12 años de escolaridad.

La prevalencia identificada en este estudio para octubre de 2020 muestra que aún hay un gran porcentaje de población susceptible de enfermar y que deben mantenerse y fortalecerse las acciones preventivas y de autocuidado, que incluyen la realización de suficientes pruebas diagnósticas, mantenimiento de restricciones de reuniones masivas, programas de vacunación, mensajes que insistan en el uso de mascarillas y mantenimiento de distanciamiento físico y programas de protección social a grupos vulnerables.

\section{ASPECTOS BIOÉTICOS}

La investigación consideró los principios de la Declaración de Helsinki, en su última enmienda realizada en la $64^{a}$ Asamblea General, el protocolo fue aprobado por el Comité Nacional expedito de la Comisión Nacional de Bioética de la Dirección Nacional de Inteligencia en Salud del Ministerio de Salud de Ecuador el 30 de septiembre de 2020.

Con el fin de garantizar el derecho de voluntariedad se obtuvo el consentimiento informado de todos los participantes. Toda la información personal fue codificada y tratada confidencialmente.

\section{INFORMACIÓN DE LOS AUTORES}

- Acurio Páez Fausto David. Doctor en Medicina y Cirugía. Master en salud Familiar y Comunitaria. Universidad de Cuenca. Dirección de Vinculación con la Sociedad. Profesor Titular de la carrera de Medicina. Cuenca-Azuay-Ecuador.

e-mail: david.acurio@ucuenca.edu.ec

ORCID: https://orcid.org//000-0003-3258-2837

- Vega Crespo Bernardo José. Doctor en Medicina y Cirugía. Magister en Investigación de la Salud. Universidad de Cuenca. Facultad de Ciencias Médicas. Docente de la carrera de Medicina (Ginecología y Obstetricia). Cuenca-Azuay-Ecuador. e-mail: bernardo.vegac@ucuenca.edu.ec ORCID: https://orcid.org/0000-0002-2545-4733

- Orellana Vintimilla Daniel Augusto. Biólogo. Doctor Exploring Pedestrian Movement Patterns. Universidad de Cuenca. LlactaLAB - Ciudades Sustentables. Departamento Interdisciplinario de Espacio y Población. Cuenca-Azuay-Ecuador. e-mail: daniel.orellana@ucuenca.edu.ec ORCID: https://orcid.org/0000-0001-8945-2035

- Charry Ramírez José Ricardo. Doctor en Bioquímica y Farmacia. Magister en Investigación de la Salud. Universidad de Cuenca. Facultad 
de Ciencias Médicas. Docente de la carrera de Medicina (Bioestadística). Cuenca-AzuayEcuador.

e-mail: ricardo.charry64@ucuenca.edu.ec

ORCID: https://orcid.org/0000-0002-9009-2548

- Gómez Ayora Andrea Ximena. Médica. Magíster en Salud Pública. Universidad de Chile. Facultad de Medicina. Escuela de Salud Pública. CuencaAzuay-Ecuador.

e-mail: axgomeza@gmail.com

ORCID: https://orcid.org/0000-0002-0032-7607

\section{CONTRIBUCIÓN DE LOS AUTORES}

APFD: Investigador principal.

VCBJ: Investigador análisis de comportamientos

OVDA: Investigador movilidad, estadística, información geográfica

CHRJR: Investigador - Estadística

GAAX: Investigadora - Estadística - análisis seropervalencia

\section{CONFLICTO DE INTERESES}

Los autores declaran no tener conflicto de intereses.

\section{FUENTES DE FINANCIAMIENTO}

Gobierno Autónomo Descentralizado Municipal del Cantón Cuenca

Universidad de Cuenca - DIUC

\section{BIBLIOGRAFÍA}

1. WHO. Global epidemiological situation WHO [Internet]. 2020 [citado 3 de marzo de 2021]. Disponible en: https://www.who.int/ docs/default-source/coronaviruse/situationreports/20200907-weekly-epi-update-4. pdf?sfvrsn=f5f607ee_2

2. Horta BL, Silveira MF, Barros AJD, Barros FC, Hartwig FP, Dias MS, et al. Prevalence of antibodies against SARS-CoV-2 according to socioeconomic and ethnic status in a nationwide Brazilian survey. Rev Panam Salud Publica/Pan Am J Public Health. 26 de octubre de 2020; [citado 4 de marzo de 2021]; 44:e135. Disponible en: https://iris. paho.org/handle/10665.2/52948
3. Pollán M, Pérez-Gómez B, Pastor-Barriuso R, Oteo J, Hernán MA, Pérez-Olmeda $M$, et al. Prevalence of SARS-CoV-2 in Spain (ENECOVID): a nationwide, population-based seroepidemiological study. Lancet [Internet]. 22 de agosto de 2020 [citado 4 de marzo de 2021];396(10250):535-44. Disponible en: https://doi.org/10.1016/

4. Servicio Nacional de Gestión de Riesgos y Emergencias del Ecuador. Situación nacional por COVID-19Infografía N¹06 [Internet]. [citado 12 de junio de 2020]. Disponible en: https://www.gestionderiesgos.gob.ec/ wp-content/uploads/2020/06/INFOGRAFIANACIONALCOVI-19-COE-NACIONAL12062020-08h00.pdf

5. Organización Mundial de la Salud. Populationbased age-stratified seroepidemiological investigation protocol for COVID-19 virus infection. World Healt Organization [Internet]. 2020 [citado el 3 de marzo de 2021]. Disponible en: https://apps.who.int/iris/ bitstream/handle/10665/331656/WHO-2019nCoV-Seroepidemiology-2020.1-eng.pdf

6. Mathur G, Mathur S. Antibody Testing for COVID-19 [Internet]. Vol. 154, American Journal of Clinical Pathology. Oxford University Press; 2020 [citado el 3 de marzo de 2021]. p. 1-3. Disponible en: https://www. ncbi.nlm.nih.gov/pmc/articles/PMC7239247/

7. INEC. Índice de proyecciones poblacionales [Internet]. Proyecciones Poblacionales. 2012 [citado 3 de marzo de 2021]. Disponible en: https://www.ecuadorencifras.gob.ec/ proyecciones-poblacionales/

8. Stringhini S, WisniakA, Piumatti G, Azman AS, Lauer SA, Baysson H, et al. Seroprevalence of anti-SARS-CoV-2 IgG antibodies in Geneva, Switzerland (SEROCoV-POP): a populationbased study. Lancet [Internet]. 2020 [citado 3 de marzo de 2021];396:313-9. Disponible en: https://github.com/HopkinsIDD/

9. Rostami A, Sepidarkish M, Leeflang MMG, Riahi SM, Nourollahpour Shiadeh $M$, Esfandyari $S$, et al. SARS-CoV-2 seroprevalence worldwide: a systematic review and meta-analysis [Internet]. Vol. 27, Clinical Microbiology and Infection. Elsevier B.V.; 2021 [citado el 3 de marzo de 2021]. p. 331-40. Disponible en: https://pubmed.ncbi. nlm.nih.gov/33228974/ 